\title{
Irradiation of a Polypropilene-glass Fiber Composite
}

\author{
L. F. MIRANDA ${ }^{1, a}$, L. H. SILVEIRA ${ }^{1, b}$, L. G. ANDRADE E SILVA ${ }^{2, c}$, \\ A. H. MUNHOZ JR ${ }^{1, d}$ \\ ${ }^{1}$ Universidade Presbiteriana Mackenzie, Rua da Consolação, 936, São Paulo-SP \\ Brazil- CEP 01302-907 \\ ${ }^{2}$ Instituto de Pesquisas Energéticas e Nucleares, Av Professor Lineu Prestes, 2242, São Paulo- \\ SP- Brazil- CEP 05508-000 \\ alfmiranda@sti.com.br, bengmateriais@mackenzie.com.br, 'Igasilva@ipen.br, \\ dahmunhoz@yahoo.com
}

Keywords: polypropilene; long glass fiber; composites; reinforced thermoplastics; ionizing radiation

\begin{abstract}
.
The use of composite materials, mainly reinforced thermoplastic has increased on the polymer industry, mainly the polypropylene resins (PP) reinforced by glass fibers (GF). The ionizing radiation can promote alterations in the polymeric chains by scission and crosslinking reactions. The objective of this work is to study the effect of the ionizing radiation in the properties of the polypropylene long fiber glass reinforced thermoplastic. Pellets with $1,3 \mathrm{~cm}$ of length, contend $15 \mathrm{wt} \%$ of the unidirectional long glass fiber were obtained by extrusion and, subsequently, the samples were molded by injection, irradiated and submitted to thermal and mechanical tests. The mechanical (tensile and impact) properties and thermal (HDT and Vicat softening temperature) of irradiated and non irradiated reinforced thermoplastic were determined. The doses of the irradiation of the samples were 30, 50 and $100 \mathrm{kGy}$ in a source of ${ }^{60} \mathrm{Co}$. The results showed a reduction in the thermal and mechanical performances indicating a degradation of the polymeric matrix.
\end{abstract}

\section{Introduction}

The combination of polymeric matrixes with reinforcing materials leads to a structure with much superior mechanical properties of the polymeric matrix, giving rise to composite materials, which have been widely used as substitutes for traditional materials [1].

The increasing interest in reinforced plastics arises from a variety of resins and reinforcing fibers, which properties can be adjusted to the different application [2].

Among the reinforcing materials there are glass fibers that are used to reinforce various types of polymers, due to their high tensile strength, high temperature resistance and high rigidity giving to the composite an excellent dimensional stability, high mechanical strength and resistance to various solvents. This type of fiber is widely used as reinforcement fiber in most thermosetting polymeric materials (polyester resins / epoxy resins) and in some thermoplastic materials, with glass fiber levels ranging, generally, between 5 and 50\% [3].

The manufacture methods of pellets reinforced with long fibers, lead to a great advance in thermoplastics reinforced with fibers development. The pellets increased from 3 to about 11 to $15 \mathrm{~mm}$ and, with this, the fibers could be oriented within the pellets giving properties hitherto never obtained, because of the size and orientation of fibers in the pellet [4].

Multinational companies have developed processes and equipments able to produce pellets of polymeric materials reinforced with long fibers, with which it is possible to obtain devices with 
high mechanical performance. The pellets of thermoplastics containing long fibers usually tend to use polypropylene and polyamide in most applications at companies like Factor, and Vertron Celstran (Ticona) [5].

The main advantage of using these reinforced thermoplastics is their weight, $30 \%$ less than by various similar materials such as steel or reinforced resin with steel inserts. Another advantage of the system is the low cost and recyclability.

Currently this type of long fiber reinforced pellet, in Brazil, must be imported. Recently, a process for obtaining this type of long fiber reinforced thermoplastic was developed in the Professional Masters Degree Program in Materials Engineering from the Presbyterian University Mackenzie [6].

The thermoplastics reinforced with long fiber can be used in structural applications which can be subjected to ionizing radiation. In addition, radiation can be used as an alternative for the development of new polymers. It is a process that can modify the properties of a material, and is a clean process, since no chemicals are used $[7,8]$.

The polymers, when exposed to gamma radiation, may suffer relevant changes in their molecular structure, resulting in two main effects: the main chain scission and crosslinking [9]. The scission of the main chain lowers the molecular weight while the crosslinking form threedimensional networks that produce an increase in molecular weight and decrease solubility. Polypropylene (PP) when exposed to radiation undergoes scission in the main chain $[10,11]$.

The objective of this work is to conduct an investigation on the effect of ionizing radiation on the mechanical properties of the thermoplastic reinforced PP /"long" glass fiber.

\section{Experimental}

\section{Materials}

This research took place by the following materials: polypropilene- Polypropylene HP-500-N, supplied by QUATTOR; monofilament glass fiber - ${ }^{\circ}$ Glass Fibers, type $30 \AA$ Rovings, model: 305E 740 TEX 10" DIL, supplied by Owens Corning OCV Reinforcements; coupling agent- PP grafted with maleic anhydride: OREVAC CA 100 suplied by ARKEMA.

\section{Methods}

The reinforced thermoplastic was prepared in a device mounted on a single-screw extruder, with $15 \mathrm{wt} \%$ of glass fibers concentration. The process of obtaining the reinforced thermoplastic pellets is the same used in the pellets for the pure PP, but with its length increased from 3 to $13 \mathrm{~mm}$ (Figure 1 (a) and 1 (b)). After wards, the samples were molded to tensile and impact tests in an injector device (Romi Model 65R). Tables 1 and 2 show the conditions for extrusion and injection molding for obtaining reinforced thermoplastics.

Samples were obtained according to the technical standards to be used in tensile test (ASTM D638-94), impact (ASTM D-256), and thermal tests of the heat distortion temperature (HDT) (ASTM D -648) and Vicat softening point (ASTM D-1525-81).

The samples were irradiated in the presence of air at room temperature, at doses of 30, 50 and $100 \mathrm{kGy}$. The irradiation was performed with gamma rays from a source of Co-60 "Gammacell" without attenuator with a dose rate of $9.25 \mathrm{kGy} / \mathrm{h}$.

The tensile test was conducted in a universal testing machine MTS-Qtest using a speed of $50 \mathrm{~mm} / \mathrm{min}$ until rupture of the sample.

Impact tests were performed on equipment Tinius Olsen Model 104 Impact at room temperature.

Tests of thermal heat distortion temperature and Vicat softening point were performed in a Tinius Olsen equipment model 94/398 HD Display. 

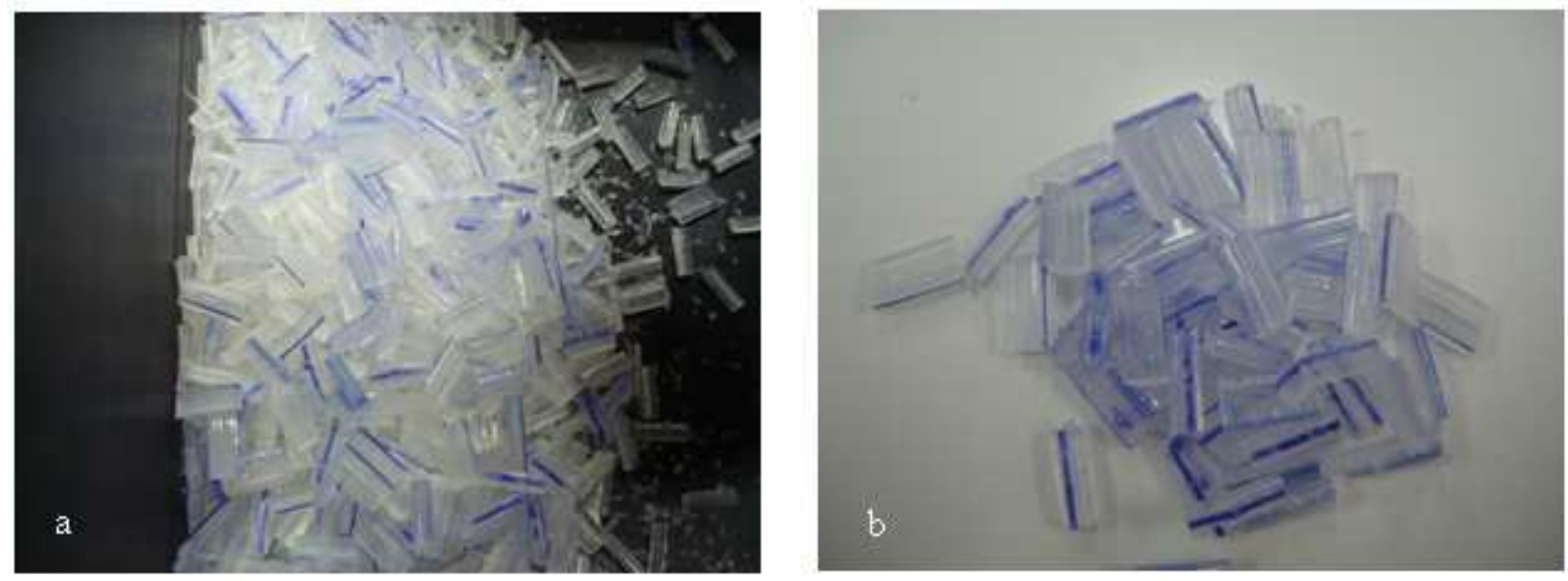

Figure 1 - Pellets with fiber dyed of blue.

Table 1 - Processing temperature of reinforced thermoplastics in the extruder.

\begin{tabular}{cccc}
\hline \multicolumn{5}{c}{ Temperatures in the extrusion zones $\left[{ }^{\circ} \mathrm{C}\right]$} \\
\hline $\mathrm{Z} 1$ & $\mathrm{Z} 2$ & $\mathrm{Z} 3$ & $\mathrm{Z} 4$ \\
195 & 190 & 180 & 170 \\
\hline
\end{tabular}

Table 2 - Molding temperatures in the injection.

\begin{tabular}{cccc}
\hline \multicolumn{5}{c}{ Temperatures in the extrusion zones $\left[{ }^{\circ} \mathrm{C}\right]$} \\
\hline $\mathrm{Z} 4$ & $\mathrm{Z} 3$ & $\mathrm{Z} 2$ & $\mathrm{Z} 1$ \\
205 & 190 & 170 & 160 \\
\hline
\end{tabular}

\section{Results and Discussion}

\section{Tensile Strength}

The results for tensile tests of reinforced thermoplastic PP / glass fiber "long" and the pure polypropylene (PP) are shown in Figures 2 and 3 and Table 3.

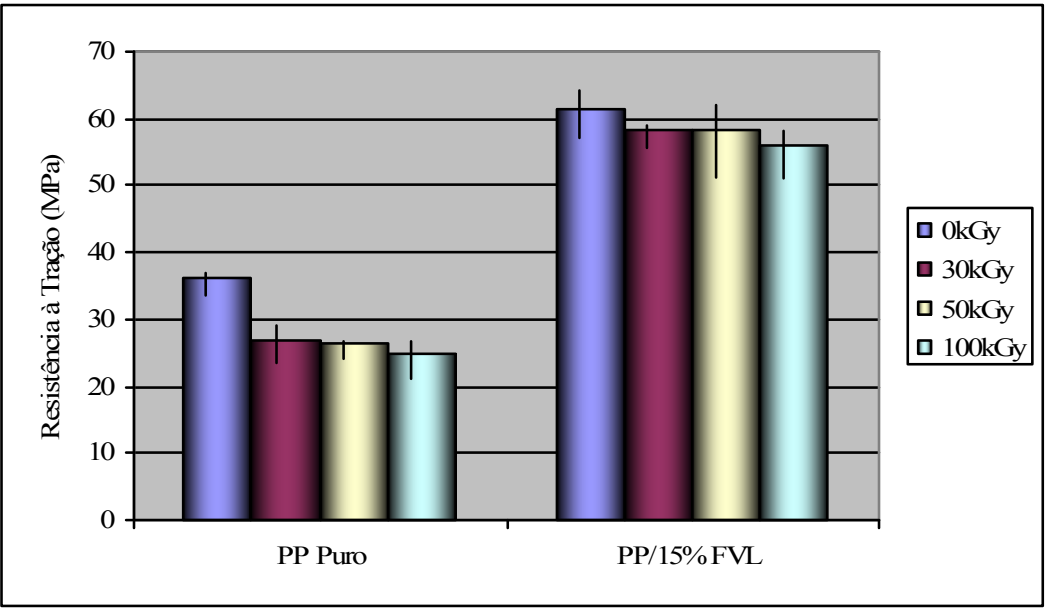

Figure 2 - Tensile strength at break of the thermoplastic reinforced PP / glass fiber "long" and the pure polypropylene (PP). 


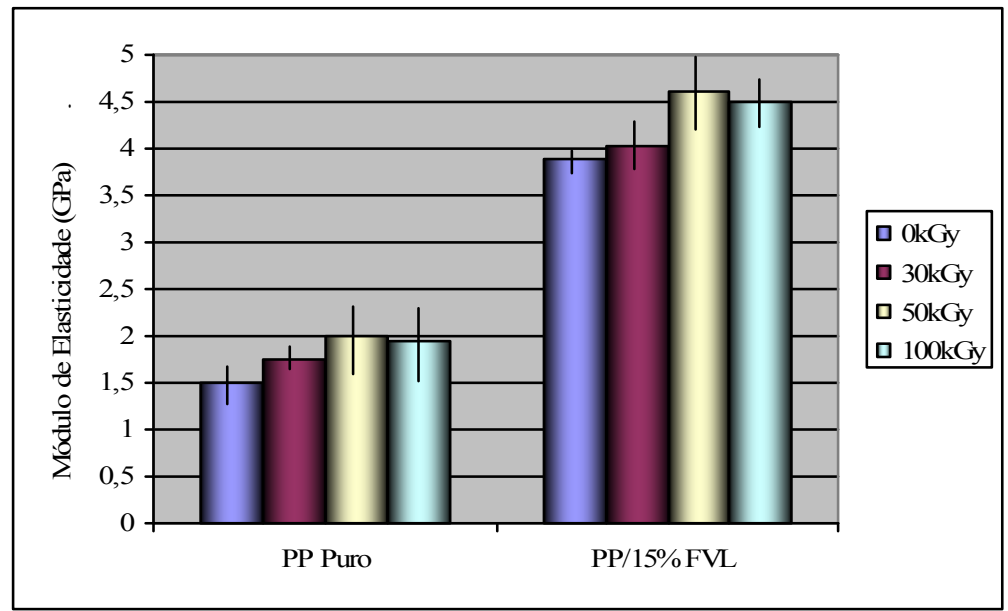

Figure 3 - Modulus of elasticity of the thermoplastic reinforced PP / fiberglass "long" and the pure polypropylene (PP).

Table 3 - Elongation at break of pure polypropylene (PP) and thermoplastic reinforced PP/"long" glass fiber

\begin{tabular}{ccc}
\hline Dose Irradiation & \multicolumn{2}{c}{ Elongation at break [\%] } \\
\cline { 2 - 3 }$[\mathrm{kGy}]$ & Pure Polypropilene (PP). & PP/"lonf'glass fiber \\
\hline 0 & $258.2 \pm 32.2$ & $3.10 \pm 0.3$ \\
30 & $15.4 \pm 2.7$ & $3.24 \pm 0.2$ \\
50 & $5.0 \pm 1.3$ & $3.24 \pm 0.2$ \\
100 & $5.0 \pm 1.0$ & $2.77 \pm 0.2$ \\
\hline
\end{tabular}

The results show that:

- The addition of "long" fiber to the polypropylene matrix almost doubles the tensile strength (94\% of increase);

- Ionizing radiation causes degradation in the polypropylene matrix, with is evidenced by the decrease in tensile strength of the materials studied. This decrease is more pronounced for pure polypropylene than for the thermoplastic reinforced with glass "long" fiber because the thermoplastic fiber-reinforced handles almost all the applied voltage. However, this decrease is not proportional to the dose of irradiation;

- The modulus of elasticity of reinforced thermoplastic is about $160 \%$ higher than pure PP. This increase is justified by the presence of long fibers.

- Ionizing radiation causes an increase in modulus of elasticity up to $50 \mathrm{kGy}$ dose for both studied materials (pure PP and PP reinforced thermoplastic / fiberglass "long"). For a dose of $100 \mathrm{kGy}$ it is observed a decrease in value. Probably, there is an increase of crystallinity of the samples, because the split caused by the radiation to the dose of $50 \mathrm{kGy}$ [9-11]. For a dose of $100 \mathrm{kGy}$ it is observed a decrease in modulus due to increased matrix degradation at this dose;

- The elongation at break of pure PP is about 83 times greater than that of reinforced thermoplastic. This difference is explained by the presence of fiberglass long;

- The degradation caused in the matrix of polypropylene by ionizing radiation is evidenced by the sharp decrease in elongation at break observed for pure polypropylene (about 93\%), while for PP reinforced thermoplastic/"long" fiberglass the decrease observed is well smaller, due to the presence of fiber. 


\section{Izod Impact Strength}

The impact tests results of reinforced thermoplastic PP/"long" glass fiber and polypropylene pure (PP) are shown in Figure 4.

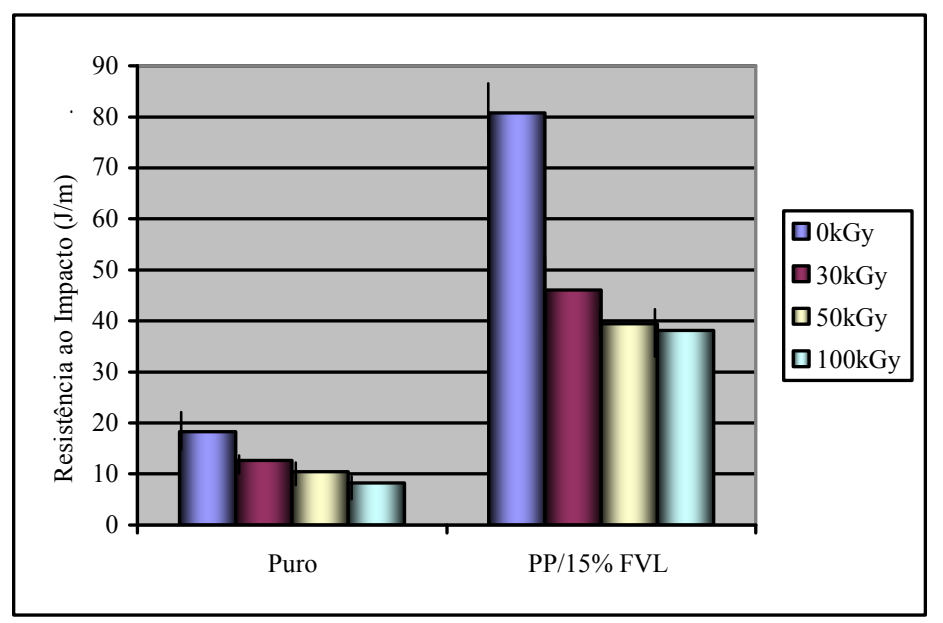

Figure 4 - Impact resistance of reinforced thermoplastic of PP/"long" glass fiber and the pure polypropylene (PP).

The results show that:

- The presence of glass fiber reinforced thermoplastic in PP / "long" glass fiber causes a significant increase in impact strength (about 441\%);

- The impact strength decreases with the irradiation dose. Probably, there is an increase of crystallinity of the samples, due to macromolecules scission caused by the radiation action. - The decrease is more pronounced for PP reinforced thermoplastic / "long", fiberglass but still presents the composite values of impact resistance superior to that of pure PP;

- The decrease in impact strength is due to degradation caused in the matrix of polypropylene by ionizing radiation.

\section{Heat distortion temperature HDT and Vicat softening point}

Table 4 presents the results for temperature heat distortion (HDT) and Vicat softening temperature tests.

Table 4 - Heat distortion temperature (HDT) and Vicat softening temperature of pure polypropylene (PP) and thermoplastic reinforced PP/ "long"glass fiber.

\begin{tabular}{|c|c|c|c|c|}
\hline \multirow[t]{2}{*}{$\begin{array}{l}\text { Irradiation Dose } \\
{[\mathrm{kGy}]}\end{array}$} & \multicolumn{2}{|c|}{$\begin{array}{l}\text { Heat distortion temperature } \\
(\mathrm{HDT})\left[{ }^{\circ} \mathrm{C}\right]\end{array}$} & \multicolumn{2}{|c|}{$\begin{array}{l}\text { Vicat softening temperature } \\
{\left[{ }^{\circ} \mathrm{C}\right]}\end{array}$} \\
\hline & $\mathrm{PP}$ & $\begin{array}{l}\text { PP/"long"glass } \\
\text { fiber }\end{array}$ & $\mathrm{PP}$ & $\begin{array}{l}\text { PP/"long"glass } \\
\text { fiber }\end{array}$ \\
\hline 0 & $96,0 \pm 3,2$ & $160,4 \pm 2,2$ & $151,8 \pm 0,2$ & $164,4 \pm 0,1$ \\
\hline 30 & $87,8 \pm 1,7$ & $153,9 \pm 1,4$ & $147,2 \pm 0,4$ & $159,5 \pm 0,3$ \\
\hline 50 & $87,7 \pm 0,5$ & $154,1 \pm 0,2$ & $147,0 \pm 0,5$ & $158,1 \pm 0,5$ \\
\hline 100 & $85,8 \pm 1,6$ & $151,5 \pm 1,2$ & $143,4 \pm 0,6$ & $154,5 \pm 0,1$ \\
\hline
\end{tabular}

The results show that: 
- The presence of glass fiber reinforced thermoplastic in PP/"long" glass fiber causes a significant increase in thermal resistance of reinforced thermoplastic. This increase is approximately $67.1 \%$ and $8.3 \%$ in the HDT in the Vicat softening point;

- The smaller increase observed for the Vicat softening point is justified because this is a spot test;

- The thermal resistance decreases with irradiation dose. The decrease is more pronounced for pure polypropylene;

- There is a tendency to decrease with the irradiation dose.

\section{Conclusions}

The results of this study indicate that the addition of the "long" glass fiber to the polypropylene matrix promotes an increase in thermal and mechanical properties of reinforced thermoplastic. It is also observed that ionizing radiation causes degradation in the polypropylene matrix evidenced by the decrease in tensile strength of the materials studied. This decrease is more pronounced for pure polypropylene than for the thermoplastic reinforced with "long" glass fiber because the fiber supports practically all the strength in the fiber-reinforced thermoplastic.

The matrix scission causes a decrease in the thermal resistance of the materials studied.

The presence of fiber increases the thermal resistance of reinforced thermoplastics. Probably, the ionizing radiation increased the crystallinity of the samples due to the matrix scission resulting from the radiation action. The increase in crystallinity causes an increase in the elasticity modulus up to $50 \mathrm{kGy}$ dose. For higher doses the matrix degradation is more pronounced resulting in a decrease in the elasticity modulus.

It is also observed that the increase in crystallinity causes a decrease in impact strength.

The degradation caused in the polypropylene matrix by ionizing radiation is evidenced by the marked decrease in elongation at break observed for pure polypropylene, whereas for reinforced thermoplastic (PP/"long" glass fiber) the decrease observed was much lower, due to the presence of "long" glass fiber.

The addition of "long" glass fiber to the polypropylene matrix increases the resistance to ionizing radiation.

\section{Acknowledgments}

The authors acknowledge to MackPesquisa by the financial support for the project development.

\section{References}

[1] J. R. Fried, Polymer science and technology, Prentice Hall- PTR, New Jersey, 1995.

[2] L. F. Miranda; M. C. Silva; N. C. Pereira In: Polymer Processing Society Proceedings -24th Annual Meeting, 2008, Salerno-Italy.

[3] PPG INDUSTRIES. Products. Long Fiber Technology (LFT).

http://corporateportal.ppg.com/na/glass/fiberglass (06/2008)

[4] Petroquímica Polialden, Extrusão Noções Básicas e Aplicações. Vol. II. $2^{\circ}$ Ed. 1992.

[5] REINFORCED PLASTIC MAGAZINE. Automotive applications. WWW revistadoplasticoreforcado.com.br/automotivo/aplicacoes (03/2009).

[6] SIVEIRA, L. H. Dissertação de Mestrado, Universidade Presbiteriana Mackenzie, 2009.

[7] C. Albano, J. Reyes, J. Gonzáles, M. Ichazo, R. Poleo, E. Davidson, Polymer Degradation and Stability, n 73 p. 39-45, Caracas, 2001. 
[8] Y. Izumi; H. Nagaike; S. Tabuse; Y. Yoshida; S.Tagawa, Radiation Physics and Chemistry, $2001,62,83$.

[9] D.W. Clegg, Irradiation Effects on polymers, Elsevier Science Publisher, New York, 1991.

[10] E. A. B Moura; A.V. Ortiz; H. Wiebeck; A. B. A. Paula; A. L. A. Silva1; L.G. Andrade e Silva. Radiation Physics and Chemistry, 2004, 71, 199.

[11] M. E. P. Ulloa; L. F. Miranda; L. G. Andrade e Silva In: International Nuclear Atlantic Conference Proceedings - INAC 2007, 2007, Santos, 2007, E13-1718. 